\title{
The Study of the Relationship between Time Management Organizational Skills and Organizational Effectiveness of Employees in Kermanshah University of Medical Sciences
}

\author{
Fereshteh Kordestani
}

\author{
Department of Education, Central Branch, Islamic Azad University (IAU), Tehran, Iran
}

Vida Azadi*

Department of Education, Central Branch, Islamic Azad University (IAU), Tehran, Iran

${ }^{*}$ Corresponding Author. E- mail: azadivida5@gmail.com

\author{
Doi:10.5901/mjss.2016.v7n2s2p128
}

\begin{abstract}
The objective of the present research is the study of the relationship between the time management organizational skills and the organizational effectiveness of employees in Kermanshah University of Medical Sciences. The study was correlational in nature and in terms of data collection. The statistical sample involved 242 employees of Kermanshah University of Medical Sciences that were selected using voluntary sampling method. The used tools were time management questionnaire of 38 items and organizational effectiveness questionnaire of 20 items. Data were analyzed using Pearson correlation coefficient. The obtained results from Pearson correlation coefficient indicated that there is a direct and significant association $(P \leq 0.01)$ between the scores of innovation ( $r=0.204)$ and job satisfaction ( $r=0.173)$ with time management organizational skills of employees in Kermanshah University of Medical Sciences; and there is also a direct and significant association(P 0.05)between the total score of time management organizational skills and the total score of organizational effectiveness ( $r=$ 0.161). In other words, by increasing the score of time management organizational skills of employees, their innovation and job satisfaction scores will similarly increase, and vice versa.
\end{abstract}

Keywords: organizational effectiveness, employees, time management organizational skills

\section{Introduction}

Throughout history, civilizations have considered its time and dimensions and there is the same consideration at the present time as well.The use of time and time management are among managers' skills which have been properly considered today. Management science experts believe that time management is the key to the success over a mountain of problems that every manager faces; and its most important advantage is that it reduces tension and with its mechanism leaves the manager with so much time to think and relax. Therefore, the aim of the management is not working hard but working properly and keeping balance in different personal and organizational aspects (Javaherizadeh, 2009).

All formal and informal organizations require management for the continuity of their operations. Lack of management results in inconsistencies, deviation fromthe goal, and waste of time and energy and leads the organizations into chaos and disintegration. Effective and efficient use of timeis an inevitable necessity for achievement in work and life.Time management includes a set of skills to control and make better use of time (Khashabi, 2010).

Time management today has a special place in management science. Thereby, organizations' efficiency will be increased following the strategies of time management, and waste of time and heavy costs in organizations will be prevented by proper use of time. Accordingly, time management is also called time control science and its proper use (Afjehei, 2006; ziapour et al, 2015).

There are several definitions for the term 'time management' like most of Humanities technical terms. According to Soroosh, time management is the presentation of practical and effective ways of saving time and restraining it in achieving greater success in work and life. These ways includesetting priorities and following them (Soroosh, 1993).

In fact, the purpose of time management skills is those which employees apply in organization environment and for proper use of time in order to achieve organization's goals and in relation to performing their professional tasks; it includes six items: setting goals, prioritizing of goals and activities, action planning, delegation of authority, managing 
communications, and managing meetings (Forosat, Eslami, 1991).

1. Setting goals. Mackenzie states that creating specific goals is the first step in time management effectively. He adds that the goals show significantlyhow the manager spends his time. If he is efficient to use time effectively, he realizes that he has made great strides towards his goals. This stepping towards goals provides an incentive for him to make faster steps and raises the goal level, too (Zali, 1996).

2. Prioritizing. According to Mackenzie, the key to success in time management is to considerthe most important things before anything and put the main focus on that work and get the rest affairs out of the mind. The privilege and feature of daily planning is that the priorities will be determined and the individual will bindhimself to focus his mind on what is prior (Eslami, 2006).

3. Action planning. Haynes divides time management techniques into two main parts including planning and eliminating waste of time factors, and states that planning is a complex process which some people can properly handle. Concerning this subject, some people are in trouble and others are so involved with activities and deadlines that have no chance for planning. He believes that planning is regarded as a key which brings a release from distressing lack of time and can help us in two waysfor bringing our life into order. First, it tells us how to get from where we are to where we want to be; second, it identifies the necessary sources to achieve the desired goal (Eghtedari, 2005).

4. Delegation of authority. It is one of the most important techniques of time management; successful managers delegate the tasks to others and perform these things with sufficient skill. One of the main reasons of delegating the authority is that it isregarded as a tool whereby the manager can focus on the most important partof work by setting his priorities and delegating less important tasks to others. This prevents the managers' waste of time (Ferasat, 2007).

5. Managing communications. According to Rowntree (1999), different forms of communicating include: writing, reading, listening, speaking in public and phoning. He states that managers have to communicate for conveying ideas and feelings and also influencing in the cognition and attitudes of each other's works. The team work would be impossible without such communication. Creating a way to communicate should be part of the manager's tasks (Rezaeian, 2004).

6. Managing meetings. Due to the importance and the helpful and effective outcomes obtainedthrough consulting with experts, meetingin state, military, and private administrations and organizations, and all regional and international organizations has been considered as one of the most important and effective ways in performing tasks that ultimately leads to saving resources. For this reason, today in developed countries holding meeting and running it has been considered as one of the most important fields in administrative sciences (Tanaomi, 2003).

Nowadays in modern world, the work's concept and form are rapidly changing. Staff in every position and level should constantly adapt themselves to progress and technology, update their information, and acquire new skills. Undoubtedly, performing these tasks takes time and in this new approach, experts believe that one of the necessary conditions in managers and employees' effectiveness is applying of time management. Emphasis on time management should be considered in all organizations and particularly in universities and also in all levels of management. We may face so many projects and programs which have not been performed or used because of the lack of time management and proper planning in due time and this has greatly brought economic and social losses (Ebrahimi, 2004).

Lakt (2004) considers applying of time management as the key to self-direction and effectiveness. He regards time control crucial to every manager wishing a fundamental result at his work.

Management experts believe that employees are the most important and valuable assets in an organization, and the most precious asset in the human life is the very limitedtime he possesses. Therefore, time is among the rarest sources that will create the timely changes and developments in all organizational components if it is used properly (Moein, 1994; Ziapour et al, 2015).

Draker(1994) considers organizational effectiveness in working properly and as a key to organization's success. An organization is effective if the noticeable outcomes of its activities equal to the organizational objectives or exceed it (Hoy, 2005; Mohammadi et al, 2014; Ziapour et al, 2014).

Sahraee (2012) believes that the greater time management people have, the higher level of job satisfaction they will have. Khonakdar (2011) concluded in his research that there is a positive and significant association between managers' time management organizational skills and organizational effectiveness.

Manzoor's research findings (2011) showed there is a positive relationship between stimulating and motivating of staff and organizational effectiveness. Sharma and Kaur (2011) concluded in their research that there is an association between structural and psychological empowerment and organizational effectiveness. The obtained resultsfrom Smith's 
research (2007) showed that all infrastructures of knowledge management and all knowledge management processes have significant impact on organizational effectiveness. Bekali and Rezaee (2010) concluded in their research that there is a significant association between dimensions of time management and organizational effectiveness. Abdolvand et al (2010) concluded in their study that there is a negative significant relationship between components of time management organizational skills and job stress.

According to the above remarks and regarding the fact that effectiveness of an organization depends on the proper and optimal use of the organization administration from resources, environment, facilities, and above all proper scheduling in doing activities, this question is raised that what relationship is there between time management skills and organizational effectiveness of employees in Kermanshah University of Medical Sciences?

\section{Materials and Methods}

The present study is correlational in nature and in terms of data collection. Statistical population of the research includes the employees at every level with bachelor and higher degrees in Kermanshah University of Medical Sciences, consisting of 650 male and female employees. Considering the frequency of given population, it should be noted that based on Morgan table a sample size of 242people in proportion to each department was selected through stratified-random method that is the representative of our statistical population.

Two standard questionnaires were used to collect data. Time management questionnaire including 35 items was designed consisting of options of never, occasionally; I have no idea, frequently. The other part is the questionnaire of the organizational effectiveness of employees including 20 items designed in 4 dimensions (organizational commitment, job satisfaction, innovation, and organizational health) and includes components of very low, low, medium, high, and very high. Both questionnaires are designed at Likert five-point scale. Validity of questionnaires has been approved using the views of 4 experienced professors and several questions were revised applying their comments. Reliability of time management questionnaire was found to be 0.79 using Chronbach's alpha and reliability of organizational effectiveness questionnaire of employees was from 0.80 to 0.90 at different steps.

Data analysis was conducted using SPSS 20 software at two descriptive and inferential statistics areas. In descriptive statistics area, measures were used including central tendency, minimum, maximum, and standard deviation as measures of dispersion, and tilt factor and elongation factor as measures of distribution; and in inferential statistics, statistical methods of the Pearson correlation coefficient was used in accordance with the research questions and the nature of data.

\section{Results}

Descriptive measures of the scores of time management skills and organizational effectiveness are presented in Table1, respectively.

Table 1- Descriptive measures of organizational effectiveness scores and the total score of time management skills

\begin{tabular}{|lcccccc|}
\hline Scale & Mean & Standard Minimum Maximum Tilt Factor Elongation Factor \\
\hline \multicolumn{7}{c}{ Deviation } \\
\hline Innovation & 18.43 & 4.64 & 7 & 29 & -0.17 & -0.13 \\
\hline Organizational Commitment & 17.73 & 4.35 & 7 & 28 & -0.10 & 0.01 \\
\hline & & & & & & \\
\hline Job Satisfaction & 11.83 & 3.56 & 4 & 20 & 0.01 & -0.29 \\
\hline Organizational Health & 11.08 & 3.50 & 4 & 20 & 0.23 & -0.19 \\
\hline Total Organizational Effectiveness & 59.08 & 14.45 & 27 & 93 & -0.01 & -0.01 \\
Time Management Skills & 115.92 & 13.80 & 82 & 148 & -0.07 & -0.65 \\
\hline
\end{tabular}

As it is observed in Table1, the mean of the innovation score of employees in Kermanshah University of Medical Sciences was computed 18.43 with minimum score of 7 and maximum of 29. Frequency distribution of normal scores is also associated with a slight tilt and negative skewness.

To answer the main question of the research, Pearson correlation coefficient was used for the score of time management organizational skills with each of the organizational effectiveness factors whose results are represented in Table 2. 
Table 2 - The correlation matrix of time management skills with organizational effectiveness factors

\begin{tabular}{|c|c|c|c|c|c|c|c|}
\hline & \multicolumn{4}{|c|}{ Innovation Commitment Satisfaction Innovation } & Health & Effectivenes & Time Management \\
\hline Innovation & 1 & & & 1 & & & \\
\hline Organizational Commitment & $* * 0.752$ & 1 & & $* * 0.752$ & & & \\
\hline Job Satisfaction & $* * 0.774$ & $* * 0.774$ & 1 & $* * 0.774$ & & & \\
\hline Organizational Health & $* * 0.661$ & $* * 0.736$ & $* * 0.768$ & $* * 0.661$ & 1 & & \\
\hline Total Organizational Effectiveness & $* * 0.899$ & $* * 0.912$ & $* * 0.915$ & $* * 0.899$ & $* * 0.866$ & 1 & \\
\hline Time Management Skills & $* * 0.204$ & 0.107 & $* * 0.173$ & $* * 0.204$ & 0.085 & $* 0.161$ & 1 \\
\hline
\end{tabular}

$\mathrm{n}=242^{* *}=\mathrm{P}<0.01^{*}=\mathrm{P}<0.05$

The results of table2 demonstrate that there is a direct and significant relationship $(P \leq 0.01)$

Between the scores of innovation ( $r=0.204)$ and job satisfaction $(r=0.173)$, with time management organizational skills of the employees in Kermanshah University of Medical Sciences; and there is also a direct and significant association $(P \leq 0.05)$ between the total scores of time management organizational skills and organizational effectiveness $(r=0.161)$. In other words, by increasing the scores of time management organizational skills of employees, their scores of innovation and job satisfaction also increase, and vice versa. According to the above results, this research question has been confirmed.

\section{Discussion and Conclusion}

The present research has been conducted to study the relationship between time management organizational skills and organizational effectiveness of employees at Kermanshah University of Medical Sciences in 2013-2014.

The results of the research first question showed that there is a direct and significant relationship between the scores of innovation, job satisfaction, and organizational effectiveness with time management organizational skills of employees in Kermanshah University of Medical Sciences. In other words, by increasing the scores of employees' time management organizational skills, the scores of their innovation, job satisfaction, and organizational effectiveness also increase, and vice versa.

According to the research results, it can be concluded that time is one of the important factors in increasing organizational effectiveness and employees who are familiar with effective and specific skills in time management willexperience greater organizational effectiveness because they canmake best use of their time and make upfor the lack of it. Accordingly, it is necessary to acquaint employees with time management skills so that organizational effectiveness and individual and society success may be achieved. Herein, Sahraee (2011) believes that the greatertime management employees have, the higher job satisfaction they will have and this satisfaction may increase people's adaptability to different working conditions, increase in efficiency, and stayingemployed.

Khonakdar (2011), who studied the relationship between time management organizational skills and the organizational effectiveness of the administrators of all branches of Islamic Azad University in Tehran province, concluded in his research that there is a positive and significant association between time management organizational skills and organizational effectiveness of the administrators. Shayanjoo et al (2011) concluded in their research that there is no association between time management organizational skills and the effectiveness of the school principals in Hamadan city.

Bekali and Rezaee (2011) concluded in their research that there is a significant relationship between dimensions of time management and organizational effectiveness. In fact, the relationship between the variable of organizational effectiveness and variables of meeting management, communication management, action planning, prioritizing the goals and activities, and delegation of authority is significant witha confidence level of 0.99. Abdolvand et al. (2010) also concluded in their research that there is a negative significant association between components of time management organizational skills and job stress.

According tothe obtainedfindings, it can be stated that organizations' effectiveness would be increased by following time management skills, and waste of time and heavy costs in organizations would be prevented by proper use of time.

\section{Limitations and Suggestions}

Among limitations and obstacles in the way of the present research wasthe restricting of the statistical sample study to running the questionnaire; therefore, interview and field research methods could be used for more accuracy.

It is suggested that this research be used in other organizations and agencies, too (This makes the power of 
results' generalizability increases). Time management status in public and private organizations should be studied eclectically.

\section{References}

Afjeei, A.A. (2006) Management of time training. Economics and Management, 32.

Alvani, M. (2005) Efficient use oftimemanagement, businessdevelopment. 12-13(3).

Charles, A. (2007). Time management training for school psychologists. Rutgers U, Graduate effectiveness. Journal of Sport Science. 12(2), PP. 120-134.

Eghtedari, M. (2005) Organization and Management. Tehran, Publish: Molavi.

Eslami, S.(2006) Functional Management time. Tabriz: cultural publications.

Hindel, T. (2004) Management of time, translation: Shafielahi. Teheran, Publisher: Sargol.

Hovi-Vin, K., Misel-Sisel, J. (2003) Theory, research and practicein educational management, Translation: Mirmaohammad Abbasszadeh, Uromieh University.

Javaherizadeh, N. (2005) Study features and time-management skills in schools in Tehran and compare it with the ideal situation. Traning and learningResearch, 12.

Lakt, J. (2004) Effective Management (Please be most effective in their work). Translation: Aminolah Alavi, First Edition, thran: public education center.

Loueis, D. (2002) Management of Time, Translation: Kamran Rohshahbaz, Tehran, Publisher:Ghoghnos, 4th Publishers.

Manzoor, Q.A. (2011) Impact of Employees Motivation on Organizational. Effectiveness. Business Management and Strategy. 3 (1), pp.1-12.

Moein.A.R. (1994) the management of Timeis a stepin increasing Productivity. Building and Installation, 3(33), pp. 153-164.

Mohammadi, M., Esfandnia, A., Rezaei, S., \& Ziapour, A. (2014) Effect of Knowledge Management on Organizational Learning in The Areas of Staff Kermanshah University of Medical Sciences. A Journal of Multidisciplinary Research. 3 (8), pp. 1-7.

Rahimnia,S., \& Sepahmansour, M.(2014). Relationship between Time Management, anxiety and quality of lifeof teachers.master thesis.Islamic Azad University Central Tehran Branch.

Rezaei, A.M., \& Moradi-Bekali, H. (2010) The Relationship between Time Management and organizational effectivenessandmental healthstaffof Naval Operationssouthern oilterminals.master thesis. Islamic Azad University of Marvdasht Branch.

Rezaeian, A. (2005) Principles of Management. Tehran, Publisher: Samt.

Sahraeei, M. (2012) the relationship between job stress and job satisfaction of employees' time management skills andcementfactories PA.Journal ofMarketing and Advertising.

Sharma, M., \& Kaur, G. (2011) Workplace Empowerment and Organizational Effectiveness. Academy of Banking Studies Journal. 10, pp. 105-120.

Shayanjoo, A., Nasiri,F.S., Hasani, J. (2013) The relationship between Organizational skills, Time Management and Efectiveness ofschooladministratorsinschool-Hamadan(2011-1012). First National Conference on Business Management, Hamedan, Toloe Farzin Science and Technology, Bu-Ali Sina University.

Smith. T.A. (2007) Knowledge management linked to strategy for organizational.

Soroush, A.H. (1993). Management of Time. Tehran, Publisher::Bozorgmehr.

Zali, M.R. (1996). Management of Time.Zamineh, 6(60, pp. 19-27.

Ziapour, A., \& kianipour, N. (2014) Relationship between organizational health and organizational citizenship behavior among hospitals staff of Medical Sciences University in Kermanshah, (One study Cross). International Journal of Management and Humanity Sciences.3, pp. 4016-4022.

Ziapour, A., Khatony, A.R., Jafari, F., \& Kianipour, N. (2015) Evaluation of time management behaviors and its related factors in the senior nurse managers, Kermanshah-Iran. Global Journal of Health Science. 7(2), pp. 366-373.

Ziapour, A., Sharafi, K., Sharafi, H., Kianipour, N., \& Shaban, M. (2015) The study of organizational health and social factors associated with (Case study: Among the staff Kermanshah University of Medical Sciences and Health Services in 2013) (One study Cross). Technical Journal of Engineering and Applied Sciences. 5 (1), pp. 147-156. 